\title{
Olive Leaf Waste Management
}

\author{
Julia Espeso ${ }^{1}$, Alejandro Isaza', Joo Youl Lee ${ }^{1}$, Pia M. Sörensen², Patricia Jurado ${ }^{2}$, \\ Roberto de Jesús Avena-Bustillos ${ }^{3}$, Mikel Olaizola ${ }^{1}$ and Juan Carlos Arboleya ${ }^{1,4 *}$ \\ ${ }^{1}$ Basque Culinary Center, Facultad de Ciencias Gastronómicas, Mondragon Unibersitatea, Donostia-San Sebastián, Spain, \\ ${ }^{2}$ Harvard John A. Paulson School of Engineering and Applied Sciences, Harvard University, Cambridge, MA, United States, \\ ${ }^{3}$ Healthy Processed Foods Research, United States Department of Agriculture, Agricultural Research Service, Western \\ Regional Research Center, Albany, CA, United States, ${ }^{4}$ BCC Innovation, Centro Tecnológico en Gastronomía, Basque \\ Culinary Center, Donostia-San Sebastián, Spain
}

OPEN ACCESS

Edited by:

José Martinez, National Research Institute of Science and Technology for Environment and Agriculture (IRSTEA), France

Reviewed by:

Frutos Carlos Marhuenda-Egea, University of Alicante, Spain

Teresa Gea

Universitat Autònoma de Barcelona, Spain

*Correspondence:

Juan Carlos Arboleya jcarboleya@bculinary.com

Specialty section:

This article was submitted to Waste Management in Agroecosystems, a section of the journal Frontiers in Sustainable Food Systems

Received: 29 January 2021 Accepted: 22 April 2021 Published: 25 May 2021

Citation:

Espeso J, Isaza A, Lee JY, Sörensen PM, Jurado $P$ Avena-Bustillos RdJ, Olaizola M and Arboleya JC (2021) Olive Leaf Waste Management

Front. Sustain. Food Syst. 5:660582. doi: 10.3389/fsufs.2021.660582
Olive trees are the oldest known cultivated trees in the world and present-day cultivation is widespread, with an estimated magnitude of 9 million hectares worldwide. As the olive oil industry has continued to grow, so has the environmental impact of olive oil production, such as the energy and water consumption, gas emissions and waste generation. The largest contributor to waste generation are the olive leaves, an abundant and unavoidable byproduct of olive-oil production due to the necessity of tree-pruning. It is estimated that an annual 1.25 million tons of olive leaf waste are generated in Spain alone, around $50 \%$ of the total world production. The leaves are currently used for biomass production or animal feed. However, because of their polyphenolic composition, olive leaves have potential in numerous other applications. In this review we analyze the chemical composition of olive leaves, and discuss current processing methods of the olive leaf waste, including thermochemical, biochemical, drying, extraction and condensation methods. We also examine current applications of the treated olive leaves in sectors relating to cattle feed, fertilizers, novel materials, energy generation, and food and pharmaceutical products. The aim of this review is to provide a resource for producers, policy makers, innovators and industry in shaping environmentally sustainable decisions for how olive leaf waste can be utilized and optimized.

Keywords: processing methods, waste management, olive leaf, olive oil, sustainable decisions

\section{INTRODUCTION}

\section{Olive Production, Consumption, and Economic Impact}

The olive tree plays an important role in the history, economy, and culture of Western civilization (Rhizopoulou, 2007). Fossil evidence indicates an origin in the Oligocene, in what is now Italy and the Eastern Mediterranean Basin, 20-40 million years ago (Waterman and Lockwood, 2007). To this day, olive trees and olive oil are deeply rooted in Mediterranean culture and play an important role in agriculture (March and Ríos, 1989).

It is believed that olive tree cultivation began in Mesopotamia (4,000 B.C), with the first records of olive crops dating to the Minoan civilization, at around 2,500 B.C.

Regarding Ancient Egypt (3100-30 BCE), the vast majority of olive plantations were located near the Nile Delta. As the cultivated olive variety did not generate significant quantities of oil, Egyptians used it primarily as a pharmaceutical and cosmetic product (Zaragoza, 1981; Meeks, 1993).

Ancient Greece had an appreciation for olive oil which is reflected in images on jars and walls such as those seen in the palace of Knossos. In fact, a symbol still seen today is the crown of olive 
branches in recognition of peace and victory. The consumption of olive oil also functioned as a marker of social class distinction (Foxhall, 2007).

Through trade and constantly traveling Greek warriors, olive tree cultivation was introduced in Italy and the consumption of olive oil grew rapidly. It has been estimated that Romans imbibed 201 of olive oil per year (Bownan and Gansey, 2009). The trade routes were based on wine, garum and olive oil, with olive oil being used in the skylights to illuminate the interior of houses. The use of olive oil became so popular that there was great competition in the stalls selling oils; one example counts more than 123 stalls selling olive oil, compared to 240 stalls selling bread (Thorndike, 2015).

As can be seen throughout history, olive trees have not only been extensively cultivated for dietary purposes, but have also become a symbol of Mediterranean culture, as well as a representation of peace, victory, and life.

Today, Greece has by far the largest per-capita consumption of olive oil, followed by Spain and Italy; but the latest figures indicate that the consumption of olive oil outside its home territory has been rising steadily. According to the Spanish Official Journal "Boletín Oficial del Estado" (2013), Spain is leading international olive oil production; with an estimated market value between 2007 and 2012 of $e 1,886$ million. This represents $4.6 \%$ of the total agricultural production in Spain. The olive tree plantations comprise around 2.6 million hectares of land in Spain, which constitutes around $14 \%$ of utilized agricultural surface, of which $28 \%$ are watered with various irrigation methods. The latest data shows that Spain produced a total of 1,793 million tons of olive oil in 2018/2019 (nearly 50\% of world production), of which 1,173 million tons were exported to the rest of the world. This data represented a 30\% increase in the previous year's figures (Agencia de Información y Control Alimentarios, 2020).

Spain is also the main exporter internationally. It is calculated that olive oil exports represent around $60 \%$ of the total trade values in Spain, with destinations to over 100 countries (Agencia de Información y Control Alimentarios, 2020).

Globally, the production volume of olive oil has tripled in the last 60 years, and in 2019/20 amounted to 3.12 million metric tons, of which the top five producers of olive oil besides Spain are Greece, Italy, Turkey and Morocco (Weber et al., 2019). Smaller industries exist in Australia and in the United States (California, Hawaii, Texas, Georgia, and Oregon); although most of the olive oil consumed in these countries is usually imported from Italy, Spain and Turkey.

Consumption of olive oil worldwide has been increasing since 2016, and in 2019/20, the global consumption volume amounted to 2.97 million metric tons. Per capita consumption is highest in Greece (over 241 per year), followed by Spain (14l per year) and Italy (14l per year). Tunisia, Portugal, Syria, Jordan and Lebanon consume around 81, and North America and Northern Europe around 0.71 . However, overall, the consumption of olive oil outside its cultivation zones has been rising steadily (Weber et al., 2019).
TABLE 1 | Overall consumption and emissions by production of 1 I of olive oil (Avraamides and Fatta, 2008).

\begin{tabular}{lcc}
\hline & Total consumption (g) & Pruning process (g) \\
\hline Consumption of crude oil & 495 & 48.7 \\
Consumption of fresh water & $3,194,000$ & 0 \\
Emissions of carbon dioxide & 3,900 & 909 \\
Emissions of nitrogen oxides & 32.2 & 3.7 \\
Emissions of sulfur dioxide & 13.7 & 1.3 \\
\hline
\end{tabular}

\section{Environmental Impact of the Olive Industry and Olive Leaves}

The olive oil industry generates by-products that can have a negative impact on the environment when not processed correctly. One of the by-products are the olive leaves, produced by the pruning and harvesting of olive trees. Normally, olive leaves get gathered with other objects such as twigs and branches. From the total pruning residues, it is estimated that the leaves constitute $25 \%$ of the dry weight. It has been estimated that the total amount of olive leaves that could be gathered in Spain alone is $\sim 750,000$ tons per year (Manzanares et al., 2017). Avraamides and Fatta (2008), reported that for everyone liter of olive oil produced, $6.23 \mathrm{~kg}$ of pruning residues (branches and leaves) are generated.

As a consequence of this production magnitude, environmental effects must also be considered. Clearly, there are different practices and techniques for the agricultural production of olives and the subsequent olive oil production, and each of these have different adverse environmental effects associated with them (Salomone and Ioppolo, 2012). However, the essence of these effects is that production of olive oil involves important resource consumption, such as energy and water, and considerable emission and waste generation (Salomone and Ioppolo, 2012). Given the magnitude of the industry, the optimization of its life cycle is crucial to limit these adverse effects.

Various life cycle analysis have been done to identify the key elements and processes that give rise to the most significant environmental problems. These studies then report the overall consumption and emissions by production of 11 of olive oil, with the total number being broken down by the various subprocesses including fertilization, irrigation, pruning... (Table 1) (Avraamides and Fatta, 2008).

A key segment is the analysis of $\mathrm{CO}_{2}$ emissions. $3.9 \mathrm{~kg}$ of $\mathrm{CO}_{2}$ per liter of olive oil is emitted. The pruning process produces $909 \mathrm{~g}$ of $\mathrm{CO}_{2}$, which is over $23 \%$ of the total $\mathrm{CO}_{2}$ emitted in the elaboration of $1 \mathrm{~L}$ of olive oil. The majority of this $\mathrm{CO}_{2}$ is generated when the pruning residues are burned, as a way to get rid of the biomass and obtain energy, creating $748 \mathrm{~g}$ of $\mathrm{CO}_{2}$ per liter of olive oil (Avraamides and Fatta, 2008).

\section{Introduction to Current Treatments and Applications of the Olive Leaves}

Currently, there are several studies and procedures to use olive leaves in different sectors such as in the food, energy and pharmaceutical industries. 


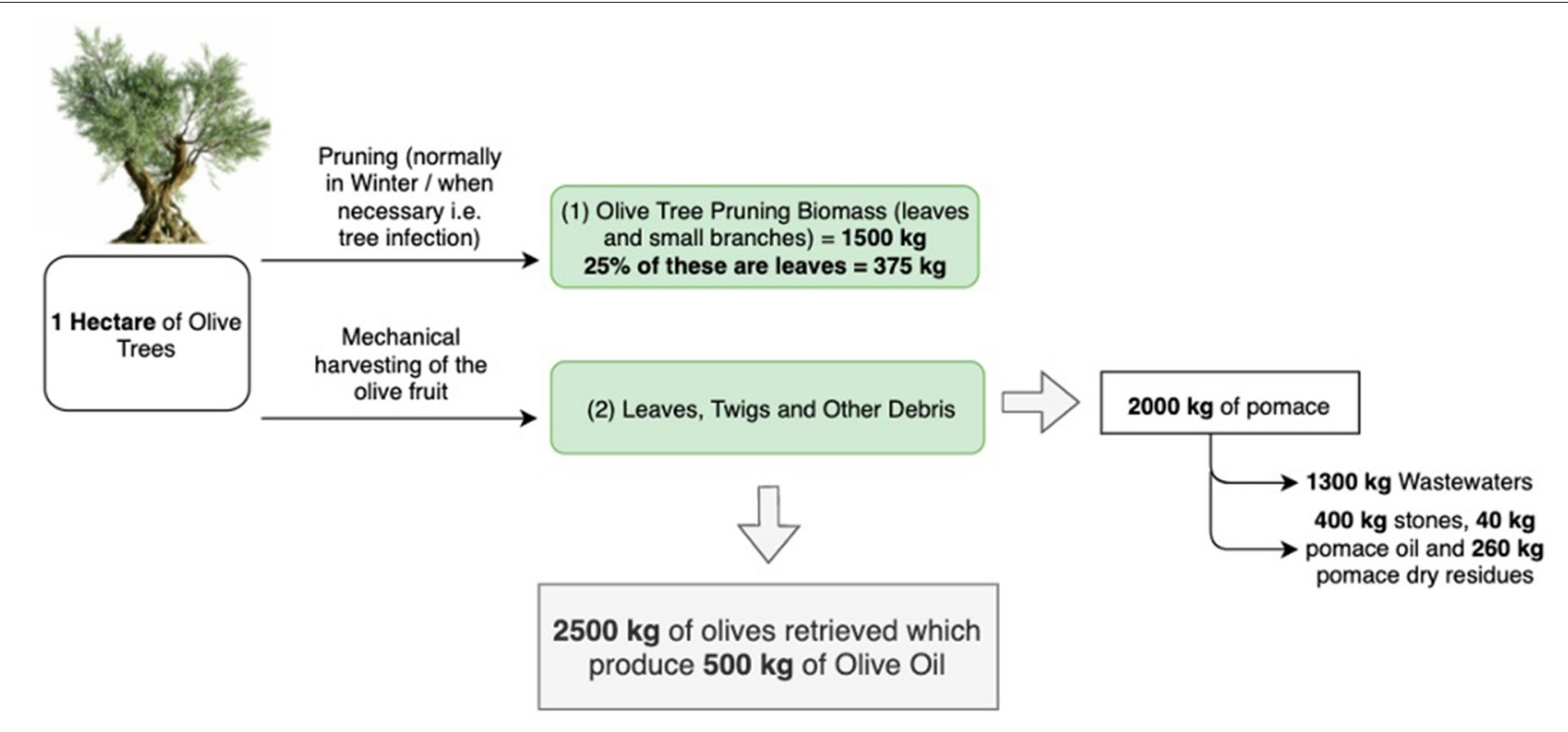

FIGURE 1 | Schematic designed to show the two processes where olive leaf by-products are generated. Reproduced from Manzanares et al. (2017).

Olive leaves' composition can be broadly divided into lignocellulosic and what the literature refers to as olive leaf extract. The lignocellulosic compounds of olive leaves consist of different concentrations of cellulose, hemicellulose and lignin. The composition is leveraged for energy production through biochemical and thermochemical treatments of the whole leaf.

However, olive leaf extracts are of special interest for their therapeutic effects and are generally used for pharmaceutical and food applications. These extracts have different classes of bisphenols, discussed in section Olive Leaves (Apostolakis et al., 2014; Romero-García et al., 2016).

In this review we further discuss current olive leaf treatments and applications. The aim is to provide a reference for producers, policy makers, and industry in shaping environmentally sustainable decisions for how olive leaf waste can be utilized and optimized.

\section{OLIVE LEAVES}

Olive leaves appear in two different steps of the olive oil production process (Figure 1). Firstly, during the pruning process, where the Olive Tree Pruning Biomass (OTPB) [leaves ( $25 \%$ dry weight basis), branches that do not exceed a centimeter in thickness $(50 \%)$ and branches that are more than a centimeter thick (25\%)] (Manzanares et al., 2017) is obtained. Secondly, as a result of the mechanical harvesting of the olive fruit (Özcan and Matthäus, 2017), in which leaves, twigs and other debris are obtained with the fruit, and which need to be separated in a further step (Souilem et al., 2017).

As formerly discussed, the pruning process is an essential process of the olive tree life cycle. Eliminating old branches gives the tree a structure, facilitating harvest and balancing out
TABLE 2 | Lignocellulosic components of olive leaves (Garcia-Maraver et al., 2015).

\begin{tabular}{lccc}
\hline & $\begin{array}{c}\text { Cellulose (wt.\%, } \\
\text { dry basis) }\end{array}$ & $\begin{array}{c}\text { Hemicellulose } \\
\text { (wt.\%, dry basis) }\end{array}$ & $\begin{array}{c}\text { Lignin (wt.\%, dry } \\
\text { basis) }\end{array}$ \\
\hline $\begin{array}{l}\text { Olive } \\
\text { leaves }\end{array}$ & 5.7 & 3.8 & 39.6 \\
\hline
\end{tabular}

production. Pruning is typically done in winter but, depending on the temperature of the region, it can be delayed until late in the season as the process can make the orchard less resistant to the cold. It is also possible to prune the trees during the summer if needed, for example, if the plant is infected. This is exceptional as during the summer months the plant grows better and it is less probable for bacteria to spread (International Olive Council, 2007).

\section{Composition and Physical-Chemical Characteristics of Olive Leaves}

As mentioned before, we can broadly divide olive leaf composition into two categories, namely:

1. Lignocellulosic materials

2. Olive leaf extract

\section{Lignocellulosic Materials}

Cellulose, hemicellulose and lignin are the building blocks that make up all leaves (Table 2). In general, chemical composition and moisture content of leaves determine aspects such as the heating value of the foliage. 


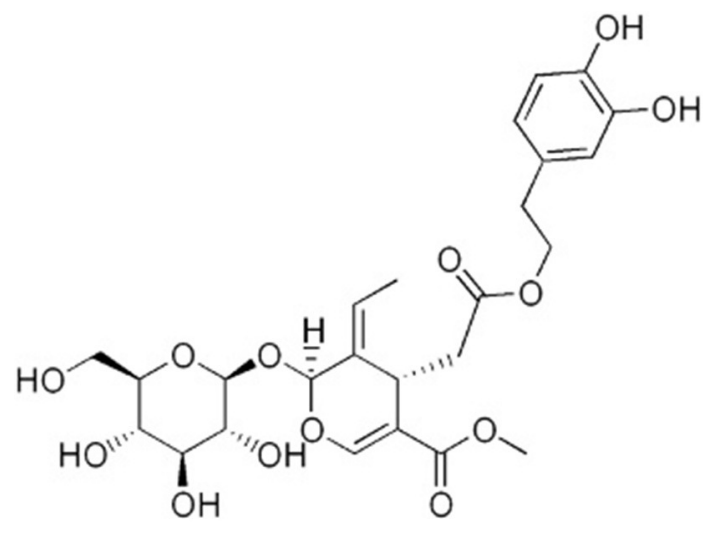

FIGURE 2 | Molecular structure of oleuropein.

\section{Olive Leaf Extracts}

There are also other molecules present in trace amounts specific to the olive tree, including:

- Oleuropeosides (including oleuropein and verbascoside)

- Flavones (including luteolin-7-glucoside, apigenin7-glucoside, diosmetin-7-glucoside, luteolin, and diosmetin)

- Flavonols, like rutin

- Flavan-3-ols

- Chatechin substituted phenols (including tyrosol, hydroxytyrosol, vanillin, vanillic acid, and caffeic acid)

Possible roles of these molecules are to defend the plant from insects and UV radiation. Among these molecules, oleuropein (Figure 2) is the most abundant of the constituents of olive leaf extract. It is present in as high as $14 \%$ in the unripe fruit, compared to $24.5 \%$ found in olive leaves, compared to $1.4 \%$ apigenin-7-glucoside, $1.4 \%$ luteolin-7-307 glucoside, and $1.1 \%$ verbascoside (Benavente-García, 2000). It has important properties, including antioxidative, antimicrobial and antiviral effects. However, using the extract without isolating the components might be beneficial due to bisphenol's synergistic effects.

These compounds are also found in the fruit of the olive tree. For example, oleuropein is. The amounts present of other polyphenols.

Overall, the polyphenolic profile of the olive leaf is affected by technological factors and industrial processes used for extraction, including: preparation, solvent type, solvent composition, solid-to-solvent ratio, particle size of the extracted material, temperature, $\mathrm{pH}$, time and temperature of extraction. In addition, the polyphenolic profile is also affected by agronomic factors such as the leaf age, degree of ripeness, geographical origin (Table 3), cultivation and phonological stage during sampling (Sahin and Bilgin, 2017).

As the leaf ages, the amount of oleuropein decreases while the amount of hydroxytyrosol increases due to the chemical and enzymatic processes that take place (Tan et al., 2003).

The antioxidant potential of oleuropein may be due to its ability to chelate metals ions, such as $\mathrm{Cu}$ and $\mathrm{Fe}$, that catalyze free radical generation reactions (Andrikopoulos et al., 2002) as well as the ability to inhibit many inflammatory enzymes such as lipoxygenases without affecting the cyclo-oxygenase pathway (Visioli et al., 2002).

\section{OLIVE LEAF WASTE MANAGEMENT}

\section{Treatments for Olive Leaves}

Given the large quantities of leaves, there are various efforts to utilize them and extract energy or various molecules. The leaf byproducts can therefore undergo various treatments before they are used for different purposes (Table 4). These treatments are summarized in the five categories below:

1. Thermochemical treatments: Combustion, gasification, and pyrolysis

2. Biochemical treatments

3. Drying methods

4. Extraction methods

5. Condensation of active components

The biochemical and thermochemical treatments are quick and cheap ways of treating big quantities of olive leaves, and therefore are the most popular treatments. However, in these treatments the leaves are used along with branches and logs that are part of the OTPB.

\section{Thermochemical Treatments}

The main purpose of thermochemical treatments is to get rid of the leaves or to obtain energy, like biofuels. For this purpose, OTPB is processed with methods such as combustion, gasification or pyrolysis.

Nowadays, combustion is the simplest way to get rid of the OTPB. Its advantages include high thermal efficiency, low operation cost and non-frequent cleaning. García Martín et al. (2020) reports that low quantities of nitrogen and sulfur in olive-pruning debris could mean this procedure is advantageous from an environmental point of view. Nevertheless, the direct combustion of the OTPB tends to be an ineffective process, as an absolute combustion rarely takes place (García Martín et al., 2020).

The gasification process involves the partial oxidation of the biomass with an amount of oxygen or steam carried out at higher temperatures. As a product a mixture of gases known as "syngas" is generated, composed by carbon monoxide, hydrogen and methane. Downsides normally are the high temperatures required for tar production $\left(>700^{\circ} \mathrm{C}\right)$ and the production of suspended solids (García Martín et al., 2020).

Pyrolisis, also known as thermal decomposition, uses high temperatures $\left(400-600^{\circ} \mathrm{C}\right)$ and is carried out under partial or complete absence of oxygen to transform the OTPB into three main products namely syngas, bio-oil and solid residues rich in carbon (García Martín et al., 2020).

In practice, most of the OTPB is burned at the roadside after harvesting. Only large diameter branches are collected and are used for domestic heating. The conversion into olive leaf pellets for subsequent heating is currently being considered. The advantages to thermochemical processes are that installations 
TABLE 3 | Total polyphenols, flavonoids and oleuropein of olive leaf extracts (Ben Salah and Abdelmelek, 2012).

\begin{tabular}{|c|c|c|c|c|c|c|}
\hline Olive varieties & $\begin{array}{l}\text { Total polyphenols } \\
\text { (mg GAE/g) }\end{array}$ & $\begin{array}{c}\text { Total polyphenolic yield } \\
\%\end{array}$ & $\begin{array}{l}\text { Total flavonoids } \\
\text { (mg CE/g) }\end{array}$ & $\begin{array}{c}\text { Total flavonoid yield } \\
\%\end{array}$ & $\begin{array}{l}\text { Oleuropein } \\
\text { (mg/g) }\end{array}$ & $\begin{array}{c}\text { Total oleuropein yield } \\
\%\end{array}$ \\
\hline Gerboua (Tunisia) & 142.21 & $99 \%$ & 125.64 & $100 \%$ & 45.02 & $79 \%$ \\
\hline Limouni (Tunisia) & 144.19 & $100 \%$ & 120.88 & $96 \%$ & 52.2 & $91 \%$ \\
\hline Chetoui (Tunisia) & 102.32 & $71 \%$ & 94.03 & $75 \%$ & 57.24 & $100 \%$ \\
\hline Chemlali (Tunisia) & 99.71 & $69 \%$ & 82.74 & $66 \%$ & 47.42 & $83 \%$ \\
\hline Sevillane (Spain) & 73.05 & $51 \%$ & 56.75 & $45 \%$ & 30.76 & $54 \%$ \\
\hline Lucques (France) & 106.8 & $74 \%$ & 97.74 & $78 \%$ & 52.12 & $91 \%$ \\
\hline Rosicola (Italia) & 91.9 & $64 \%$ & 76.01 & $60 \%$ & 48.48 & $85 \%$ \\
\hline Meski (Italia) & 110.03 & $76 \%$ & 91.32 & $73 \%$ & 52.63 & $92 \%$ \\
\hline
\end{tabular}

TABLE 4 | Treatments for olive leaves with corresponding description, advantages, and disadvantages.

\begin{tabular}{|c|c|c|c|}
\hline Name of treatment & Description & Advantages & Disadvantages \\
\hline Biochemical & $\begin{array}{l}\text { Two types: Anaerobic digestion } \\
\text { and bioethanol production }\end{array}$ & $\begin{array}{l}\text { Treating large volumes of olive leaves. } \\
\text { Bioethanol production is a promising } \\
\text { alternative to fossil fuels (greener) }\end{array}$ & $\begin{array}{l}\text { Multiple steps required before } \\
\text { fermentation (pretreatment, hydrolysis) } \\
\text { (Bioethanol production) } \\
\text { Required pretreatment is not cost-effective } \\
\text { (Bioethanol production) }\end{array}$ \\
\hline Thermochemical & $\begin{array}{l}\text { Conversion routes of biomass to } \\
\text { heat, power, steam, or electricity } \\
\text { Three types: Combustion, } \\
\text { gasification, pyrolysis }\end{array}$ & $\begin{array}{l}\text { Quick, cheap ways of treating big } \\
\text { quantities of olive leaves. Easy } \\
\text { High thermal efficiency, low operation } \\
\text { cost (Combustion) }\end{array}$ & $\begin{array}{l}\text { Waste management problem of liquid } \\
\text { residues (pyrolysis) } \\
\text { Cleaning of gases and suspended solids } \\
\text { from tar (gasification) } \\
\text { Ash-related problems, like } \\
\text { agglomeration/deposition (gasification) }\end{array}$ \\
\hline $\begin{array}{l}\text { Extraction and } \\
\text { condensation methods }\end{array}$ & $\begin{array}{l}\text { Methods by which valuable } \\
\text { compounds (such as } \\
\text { polyphenols) are separated } \\
\text { selectively from the matrix } \\
\text { (extraction), and increased } \\
\text { concentration (condensation) }\end{array}$ & $\begin{array}{l}\text { Olive leaves are an inexpensive, } \\
\text { renewable, and abundant source of } \\
\text { polyphenols, which have important health, } \\
\text { and functional benefits }\end{array}$ & $\begin{array}{l}\text { Big variability in the quantity of } \\
\text { polyphenols, flavonoids, and secoiridoids } \\
\text { depending on technological and } \\
\text { agronomical factors } \\
\text { Solvent waste }\end{array}$ \\
\hline
\end{tabular}

are less bulky, simpler and smaller while the biochemical ones must use heat and gas immediately. However, there are some disadvantages to these practices, especially concerning the generation of waste products. Pyrolysis can be performed under different conditions: inert atmosphere $\left(\mathrm{N}_{2}\right)$ or pyrolysisbased circular system (which is a pyrolysis at $600^{\circ} \mathrm{C}$ under $\mathrm{He}$ atmosphere); however, it has been concluded that microwaveassisted pyrolysis of the pruning biomass can be an appropriate method for yielding useful chemicals and fuels, and hence represents a possibility for reducing the environmental risks that are associated and involved in the disposal (García Martín et al., 2020). Other study has used different agricultural residues, including the OTPB in order to use them as soil amendment, and analyzed in depth the characteristics of each waste depending of the temperature and the time it was applied; the research concluded that the optimal factors to get a high $\mathrm{pH}$ product is to put the temperature at $500^{\circ} \mathrm{C}$ during a residence time higher than an hour (Campos et al., 2020).

\section{Biochemical Treatments}

Biochemical processes are another possible treatment for the OTPB and include anaerobic digestion and bioethanol production.
Anaerobic digestion consists of introducing the biomass into a digester without oxygen, followed by the addition of a bacterial culture which is responsible for biogas production. There are scarce references in the literature of methane generation from OTPB. However, the finest OTPB particles have found to achieve the highest methane yield (176.5 Nm3 per $t$ volatile solids, which accounted for $93.5 \%$ gains over the untreated OP), due to their high nitrogenous matter and low $\mathrm{C} / \mathrm{N}$ ratio found in this substate, which makes it suitable for anaerobic digestion. Nonetheless, olive mil waste has a higher potential for anaerobic digestion and hence methane production. Since around 10-12 million cubic meters of Olive Mill Wastewater are produced yearly, it is possible that researchers have focused on this issue-explaining the lack of information on methane production from OTPB (Costa et al., 2018).

As the pruning biomass has a high cellulose and low lignin content, it is an ideal substrate for bioethanol production. Currently, the bioethanol production encompasses four stages, namely: pre-treatment, hydrolysis of polysaccharides into monomer sugars, fermentation of monomer sugars to ethanol, and ethanol concentration. 
These different stages are discussed in the "Energy generation" section.

\section{Drying Methods}

There are several methods used to dry the whole leaves with the purpose to concentrate the bioactive compounds present in the leaves. Various studies have measured the impact of each method. The most common procedures are solar drying, infrared drying, microwave drying and freeze drying.

Solar drying consists of drying the leaves by convective heat through solar power or specialized equipment. Studies have investigated the quality attributes of dried leaves in terms of color, total phenols and radical scavenging activity while controlling the temperature and airflow. The results found significant differences between the temperature, the total phenols and scavenging activity. At lower temperatures, antioxidant capacity was higher but total phenols decreased. Otherwise antioxidant capacity was lower when the leaf was dried at higher temperatures and flow rates (Bahloul et al., 2009).

Infrared drying uses infrared radiation to reduce the moisture in the leaves. Some investigations have observed the difference between fresh and blanched leaves dried at different temperatures, studying its total phenolic content and color difference between each sample. The results show a higher concentration of total phenols around $50^{\circ} \mathrm{C}$, and an increase in luminance and greenness around $50-60^{\circ} \mathrm{C}$ (Boudhrioua et al., 2009).

Microwave drying also uses radiation to reduce the water content of the leaves, while freeze drying uses pressure and low temperatures to obtain the same result. A study compared the total oleuropein and other phenols present in the leaves depending on different drying methods (microwave, freeze, vacuum, oven, and ambient air). The most effective procedures were shown to be microwave drying and freeze drying, the latter of which had a decrease of the water content of 5\% (Sahin et al., 2018).

\section{Extraction Methods}

Extraction and condensation treatments are employed when the bioactive compounds present in olive leaves are used as natural additives in the food and medicine industry. Now, more than ever, it is necessary to explore greener techniques that are respectful of the environment, present no health risks, and maintain the bioactivity of the molecules.

The three most common extraction methods for the compounds in olive leaves are (1) supercritical fluid extraction, (2) ultrasound assisted extraction and (3) maceration. The main differences between these methods are the extraction yields, solvents, and cost.

Supercritical fluid extraction is a versatile technique used for extraction and precipitation of bioactive molecules. Supercritical fluids have a lower viscosity than liquids and therefore are more hydrodynamic. They have a lower surface tension which enables a high penetrability through porous surfaces (Cejudo Bastante, 2020). Studies on olive leaf supercritical fluid extraction use carbon dioxide and ethanol. The most effective parameters for this purpose are 120 bar pressure and $55^{\circ} \mathrm{C}$, however extraction yields are far from optimal, with an average extraction yield of 9.35\% (Cejudo Bastante, 2020).

Ultrasound assisted extraction is a time-efficient way of extracting bioactive compounds. When ultrasound waves are applied, intense pressure and temperature gradients within the material are created. This induces physical structural disruption due to cavitation, which enhances mass transfer and the release of the intracellular substances into the extraction medium. Studies claim that it can also get viable extraction yields without the need of using high amounts of solvents or high temperatures, making it more sustainable. The main downside of this process is the cost of the machinery (Cifá et al., 2018).

A common way of recovering phenolics is via maceration. In this process, the leaves are dried, crushed and macerated in a range of solvents including acetonitrile, ethanol or distilled water at different $\mathrm{pH}$ values. The extracts are then filtered, and the solvents removed from the filtrate using a rotary evaporator (Ghomari et al., 2019). The downsides to this technique include hugely variable results depending on solvent (they range from 24.9 to $144.2 \mathrm{mg}$ GAE/g dry matter), as well as lower extraction yields in comparison to supercritical fluid extraction or ultrasound assisted extraction techniques. Also, longer times and higher temperatures are required compared to ultrasound assisted extraction, and therefore this procedure is considered less environmentally friendly (Cifá et al., 2018).

In addition to the three methods discussed above, there are countless other extraction methods used to extract valuable compounds from olive leaves, employing:

a. Eco-friendly deep eutectic solvents (Athanasiadis et al., 2017)

b. Low-transition temperature mixture (Karageorgou et al., 2017)

c. Solvent-free microwave-assisted extraction (Sahin et al., 2017)

d. Instant controlled pressure drops (Mkaouar et al., 2016)

e. Steam explosion (Romero-García et al., 2016)

f. Heated water/glycerol mixtures (Apostolakis et al., 2014)

g. Pressurized liquid extraction (Herrero et al., 2011)

The highest polyphenolic content reported amongst these is obtained by using eco-friendly deep eutectic solvents (Athanasiadis et al., 2017), while the lowest polyphenolic content is obtained with the solvent-free microwave-assisted extraction (Sahin et al., 2017).

\section{Condensation Methods}

Once the olive leaf extract has been extracted from the olive leaves with the techniques discussed above, there are various methods for condensing it to increase the concentration of valuable compounds. The two most popular methods for this purpose are freeze drying and spray-drying.

Freeze drying is a procedure which generally uses liquid nitrogen at $-57^{\circ} \mathrm{C}$ and a pressure of 0.05 bar for $24 \mathrm{~h}$ to freeze the leaves (Ghelichkhani et al., 2019). Spray drying is a technique which converts the frozen olive leaf extract into a powder using a spray drier (Ghelichkhani et al., 2019).

Results show that when freeze and spray drying methods are compared, the former yields a higher phenolic content of 446.63 \pm 7.6 (mg gallic acid per g dry matter), while the latter yields 
TABLE 5 | Active compounds in olive leaf extract and their reported pharmaceutical effects.

\begin{tabular}{|c|c|c|c|}
\hline Pharmaceutical effect & Active compound & Report & References \\
\hline Antioxidant capacity & Oleuropein & $\begin{array}{l}\text { Compounds shown as antioxidants that prevents } \\
\text { formation of radicals. }\end{array}$ & Andrikopoulos et al., 2002 \\
\hline Anti-atherosclerotic effect & Oleuropein & $\begin{array}{l}\text { Polyphenols have shown capacity to reduce } \\
\text { incidence of heart disease. }\end{array}$ & Singh et al., 2008 \\
\hline Cardioprotective effects & Oleuropein & $\begin{array}{l}\text { Attenuates cardiotoxicity of lipid peroxidation } \\
\text { products, such as Adriamycin. }\end{array}$ & Andreadou et al., 2007 \\
\hline Anti-inflammatory activity & Oleuropein, Hydroxytyrosol & $\begin{array}{l}\text { Reported as inhibitors of molecules involved in } \\
\text { various inflammatory pathways }\end{array}$ & Visioli et al., 2002 \\
\hline Anti-inflammatory activity & Luteolin, Apigenin & $\begin{array}{l}\text { Luteolin and Apigenin shown anti-inflammatory } \\
\text { activity in vitro. }\end{array}$ & De la Puerta et al., 1999 \\
\hline Antimicrobial activity & $\begin{array}{l}\text { Oleuropein, hydroxytyrosol, } \\
\text { elenolic acid }\end{array}$ & $\begin{array}{l}\text { Products from the hydrolysis of phenolic } \\
\text { compounds are responsible for antimicrobial activity. }\end{array}$ & Sudjana et al., 2009 \\
\hline Hypoglycemic effect & Oleuropeoside & $\begin{array}{l}\text { Beneficial in inhibiting hyperglycemia and oxidative } \\
\text { stress induced by diabetes }\end{array}$ & Gonzalez et al., 1992 \\
\hline Rheumatoid arthritis & Oleuropein & $\begin{array}{l}\text { Responsible for prevention and treatment of } \\
\text { rheumatoid arthritis in animal models. }\end{array}$ & Impellizzeri et al., 2011 \\
\hline Anti-cancer & Dry olive leaf extract & $\begin{array}{l}\text { In vitro studies reported various outcomes when } \\
\text { applied in combination with different } \\
\text { chemotherapeutics }\end{array}$ & Mijatovic et al., 2010 \\
\hline
\end{tabular}

higher values or antioxidant activity $(96.57 \pm 0.19 \%)$, inhibitory effect $(0.44 \pm 0.32 \mu \mathrm{g} / \mathrm{ml})$, tannin content $(128.71 \pm 0.26 \mathrm{mg}$ gallic acid per $\mathrm{g}$ of dry matter) and total flavonoids (396.43 \pm $0.25 \mathrm{mg} 425$ quercetin per g of dry matter) (Ghelichkhani et al., 2019).

\section{OLIVE LEAF APPLICATIONS}

As a result of the treatments, the olive leaves may have different applications that can be divided into distinct areas. The main applications for olive leaves can be divided into:

- Cattle food, fertilizer and compost production

- New materials

- Pharmaceutical

- Energy generation

- Food products

\section{Cattle Food}

As is the case with most by-products of the olive oil industry, not just the whole leaves, but also the mill waters, currently serve as cattle feed. Although the leaves' composition is variable and dependent on origin, humidity, and storage conditions, they can contribute arginine, leucine and valine to the diets of cattle. Protein synthesis in goats and sheep that have been fed with olive leaves is similar to that obtained with barley feed (Balcells et al., 1993).

The digestibility of olive leaves is low and can decrease if the leaves are dried; however, the digestibility can be increased upon treatment with ammonia or complemented with a mixture of barley or fava beans (Molina-Alcaide and Yáñez-Ruiz, 2008). One of the main challenges of leaves serving as cattle food is that the olive tree requires treatments with copper sulfate, which can lead to liver activity dysfunction in cattle (Howell and Gawthorne, 1987).

\section{New Materials}

Olive leaf extract obtained by extraction and condensation methods possesses antimicrobial properties against foodborne pathogens such as Escherichia coli, Staphylococcus aureus, Pseudomonas aeruginosa, Lactobacillus plantarum or Campylobacter jejuni, among others (Korukluoglu et al., 2010; Keskin et al., 2012). For this reason, it has been explored if the extract can be incorporated through supercritical impregnation into "active containers" that can help in food preservation and increased shelf-life. Phenolic compounds are highly bitter, so these efforts have taken sensory properties into special consideration (Cejudo Bastante et al., 2019).

\section{Pharmaceutical}

Olive leaves have been used by traditional medical practitioners for thousands of years as they were thought to speed wound healing, sooth rashes and cleanse the liver. They were mainly ingested orally for healing of intestinal and stomach diseases and to treat bronchial asthma; alternatively they were chewed as a mouth cleanser or infused in hot water to treat high blood pressure (hypertension) and induce urination (diuresis) (Assessment report on Olea europaea L., folium., 2017).

In the last decades polyphenolic and secoroiridoids secondary metabolites of olive leaves have been extracted and their potent biological activities studied in vitro or in vivo (Assessment report on Olea europaea L., folium., 2017).

The main pharmacological effects of olive leaves reported in the literature are described below (Table 5): 


\section{a. Antioxidant Capacity}

Olive leaves have the highest oxygen scavenging activity amongst the different parts of the olive tree due to their high polyphenolic content. For example, oleuropein content in olive oil ranges from 0.005 to $0.12 \%$, while for olive leaves it ranges from 1 to $14 \%$ (Japón-Luján et al., 2006). Oleuropein is a potent antioxidant with anti-inflammatory properties and prevents the formation of radicals due to its ability to chelate metal ions $(\mathrm{Cu}$ and $\mathrm{Fe})$ which catalyze free radical generation reactions (Andrikopoulos et al., 2002).

\section{b. Anti-atherosclerotic Effect}

Cardiovascular effects of olive leaves have been thoroughly studied, and have been especially attributed to cultivar species that have the highest concentrations of oleuropein and oleacin (Lasserre et al., 1983). These have shown a capacity to dilate coronary blood vessels and consequently reduce the incidence of heart disease. Furthermore, polyphenols have been found to cause in vitro platelet activation in healthy, non-smoking males (Singh et al., 2008).

\section{c. Cardioprotective Effects}

Doxorubicin, which is an anthracycline antibiotic clinically known as Adriamycin, has a limited use because of its undesirable serious cardiotoxic side effects. The in vivo effect of oleuropein on Adriamycin treatment has been investigated, and indicates that oleuropein attenuates cardiotoxicity by inhibiting lipid peroxidation products, decreasing oxidative stress, and reducing nitric oxide species in cardiomyocytes (Andreadou et al., 2007). These studies were conducted in rats, and results from human studies are still pending.

\section{d. Anti-inflammatory Activity}

Both oleuropein and hydroxytyrosol are inhibitors of leukotriene B4 generation, which is involved in various inflammatory pathways (Visioli et al., 2002). In addition, luteolin and apigenin, which are also present in olive leaves have shown antiinflammatory activity in animal models as well as anti-allergic effects in vitro (De la Puerta et al., 1999).

\section{e. Antimicrobial Activity}

The hydrolysis products of oleuropein, hydroxytyrosol and elenolic acid are responsible for the antimicrobial activity of olive leaves, particularly against Bacillus subtilis, B. cereus, Staphylococcus aureus, Salmonella typhi, Vibrio cholerae, V. parahaemolyticus and Micrococcus sp, as well as its anti-protozoal, anti-fungal and antiviral properties (Sudjana et al., 2009).

Olive leaves may also be useful in cases where prolonged use of antibiotics encourages development of bacteria genera which pose a major resistance problem such as Klebsiella and Pseudomonas (Neu, 1992).

\section{f. Hypoglycemic Effect}

Oleanolic acid, a triterpenoid obtained from olive leaves, is a specific and potent TGR5 agonist. This molecule has a potent anti-hyperglycemic activity, which contributes to the antidiabetic effect of Olea europaea leaves (Sato et al., 2007).

\section{g. Rheumatoid Arthritis}

Oleuropein is the compound responsible for the prevention and treatment of rheumatoid arthritis in animal models, and has similar benefits on osteoarthritis, especially in improving joint swelling and preventing production of inflammatory cytokines (Impellizzeri et al., 2011).

\section{h. Anti-cancer}

The anticancer potential of dry olive leaf extract represents the net effect of multilevel interactions between different biologically active compounds from the extract, cancer cells and conventional therapy. Studies have focused on the impact of leaf extract in the B16 mouse melanoma cell line in vitro, and results indicate that when dry olive leaf extract is applied in combination with different chemotherapeutics various outcomes (including synergistic and antagonistic effects) are obtained. This requires caution in the use of the extract as a supplementary antitumor therapeutic (Mijatovic et al., 2010).

In addition to the effects outlined above, recent studies have shown that olive leaf extract can be helpful in combatting osteoporosis (Gong, 2012), and improving the immune system (Ilias et al., 2011).

\section{Energy Generation}

Energy production from olive tree cultivation is well-established. It is estimated that $80 \%$ of the total Andalusian by-product use (50\% of European Union production) goes to energy generation (47\% for electricity and 33\% for thermal energy). However, only a small amount of the pruning biomass (including the leaves) is directly used as a raw material in power generation plants.

Olive tree biomass can generate energy through the degradation of lignocellulosic material (Romero-García et al., 2014). A conversion of the carbohydrates contained in the lignocellulosic material into fermentable sugars remains a key issue for biorefineries, who are trying to provide a viable route for biofuels or bioproducts. By pruning old leaves, we can generate a raw material for power generation, but the implementation of different processes is needed to get the best yield from enzymes. This process is divided into pretreatment, hydrolysis and fermentation by microorganisms (Figure 3).

\section{Pretreatments}

There are several studies mentioning several ways to pretreat the leaves to obtain a higher yield of the lignocellulosic materials. One of those ways could be the hydrothermal treatments; this procedure uses the biomass in water at high temperatures and pressures; the ionization of the water causes the release of proton particles that act as catalysts for the autolysis process to break the groups of acetyl present in the form of ester in the hemicellulose and consequently release acetic acid. This process has certain favorable characteristics, for example, it reduces the effect of corrosion, it recovers compounds derived from hemicellulose and increases digestibility of cellulose from solid treatises (Alvira et al., 2010). Sa Santos et al. (2017), reported an increase of cellulose and decrease of hemicellulose after handling the OTPB to a steam explosion pretreatment. 


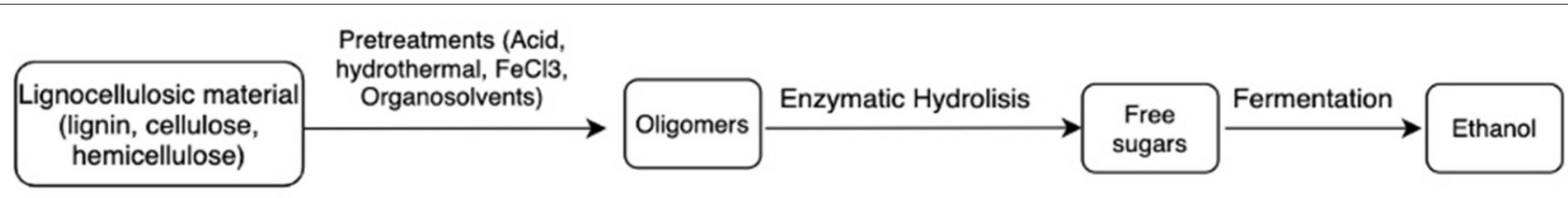

FIGURE 3 | Schematic showing the steps required to convert olive leaves into ethanol.

Other pretreatment possible is to use an acidic environment (usually sulphuric acid), in which the hemicellulose fractions of the biomass are solubilized to make cellulose more accessible to the enzymes. This treatment is already common in the industrial world and is used to treat various types of foods with high lignocellulose content. It has presented favorable results in many applications (Cara et al., 2008; Díaz-Villanueva et al., 2012). Nevertheless, Cara et al. (2008), concludes that a better yield is obtained after mixing this acid pretreatment with a hydrothermal treatment from before.

An additional pretreatment is to use organic solvents, such as ethanol, methanol, ethylene glycol, acetone or glycerol that are used prior to enzymatic hydrolysis. Díaz et al. (2011) compared the glucose yield of different pretreatments methods and concluded that a higher yield could be obtained after using organic solvents.

Lastly, a potential pretreatment is the use of inorganic salts as catalysts to solubilize hemicellulose. Pretreatment with $\mathrm{FeCl}_{3}$ could alter most of the ester and ether linkages between lignin and carbohydrate with no effects on designation (Liu et al., 2009). This pre-treatment with $\mathrm{FeCl}_{3}$ eliminates the hemicellulose and improves cellulose accessibility to cellulase. All this happens in an environment with high temperatures that favor hydrolysis increasing the surface area and widening the pores (Liu et al., 2009). However, studies have only been applied to other biomasses and not specifically to the OTPB.

\section{Enzymatic Hydrolysis}

The purpose of hydrolysis is simple: depolymerize the polysaccharides contained in the pretreated lignocellulosic substrate. Lignocellulose has a very complex structure that requires intervention of various enzymes at specific concentrations to obtain complete hydrolysis.

Several studies have examined hydrolysis with different types of pre-treatments, with different results and percentages of sugars (Díaz et al., 2011). Many of them use different amounts and types of enzymes depending on the treatment (Romero-García et al., 2014). The enzymes that are most commonly found in the literature are hemicellulases, cellulases, arabinases, and xylanases.

\section{Fermentation}

The most abundant sugars obtained from the hydrolysis of lignocellulose are glucose and xylose. These sugars present a difficulty when being fermented, as they need two different microorganisms which cannot act simultaneously due to requiring different ambient conditions. Therefore, the hydrolysates are detoxified to reduce the inhibitory effect of the compounds present in the hydrolysate obtained after the pre-treatment (Díaz et al., 2009; Negro et al., 2014).

Saccharomyces yeast is the first option for fermentation, while other options include microorganisms such as Pachysolen tannophilus, Candida shehatae, and Pichia stipites that have the ability to ferment C5 sugars. Olive pruning sugars from the cellulose and hemicellulose fraction can be converted to ethanol by a simultaneous process of saccharification or fermentation or by separate enzymatic hydrolysis and fermentation process. Sa Santos et al. (2017) reported that once fermentation is done, a lignin residue is left in the process.

\section{Food Uses}

Due to its promising components, the use of olive leaf extract as an additive to foods has been the source of much investigation, creating several promising and actual applications. Approaches include (a) improving the nutritional profile, (b) enhancing chemical stability with regard to lipid oxidation, or (c) stabilizing foams and emulsions.

Studies aimed at improving the nutritional profile with olive leaf extract have focused on addition of either a pure extract, or encapsulated compounds in oils, in foods such as smoothies, baked snacks, yogurts, and meat products (Tavakoli et al., 2018; Caponio, 2019). Other studies affirm that the improvement of antioxidant activity could result in an oxidative stability improvement, therefore, the extension of the shelf life and, in some cases, it is also related to the improvement of the nutritional value of foods (Shahidi and Ambigaipalan, 2015). Furthermore, if the product is enriched with olive leaf extract, the cultivable bacteria, yeasts, and molds decrease dramatically, in addition to having a greater impact if it is stored in refrigeration (Caponio, 2019).

Studies evaluating the use of olive leaf extract as a natural preservative focus on the preservative effects of plant polyphenols. These compounds can have a crucial role in reducing lipid oxidation and hence extending shelf-lives of foods, which indirectly implicates the reduction of food waste. The industry has tried to extend shelf lives by adding synthetic antioxidants to fat-containing foods such as butylated hydroxyanisole (BHA), butylated-hydroxytoluene (BHT), propyl gallate (PG), and tert-butylhydroquinone (TBHQ) (Difonzo et al., 2019). Recent reports have shown these compounds may be implicated in health risks including carcinogenesis (Gultekin et al., 2015). Therefore, consumers have begun to reject them. However, in the last few years, new procedures based on green processes have been developed to improve the quality of these edible oils by enriching them with natural extracts rich in 
polyphenolic compounds. These are good alternatives as they are readily available as industrial wastes, maintain a potential preservative effect, and present positive effects on human health (Difonzo et al., 2019).

Several studies investigate the ability of olive leaf extract to stabilize emulsions and foams. For example, the surface active properties of the polyphenols present in olive leaves have been studied at acidic $\mathrm{pH}$ and in green solvents like ethanol and water. Therefore, olive phenolics can influence colloidal and gelling behavior of biopolymers (Flamminii et al., 2019) as well as enhance stability of emulsions and foams. This implies that oliveleaf extracts can exploit important technological functionalities and potentially serve as promising functional ingredients. From an industrial point of view, these results could open interesting opportunities and contribute to enhancing the exploitability of polyphenolic extracts as multifunctional ingredients (Flamminii et al., 2019). The principal limitation of this application reported in the literature is that the emulsions produced were

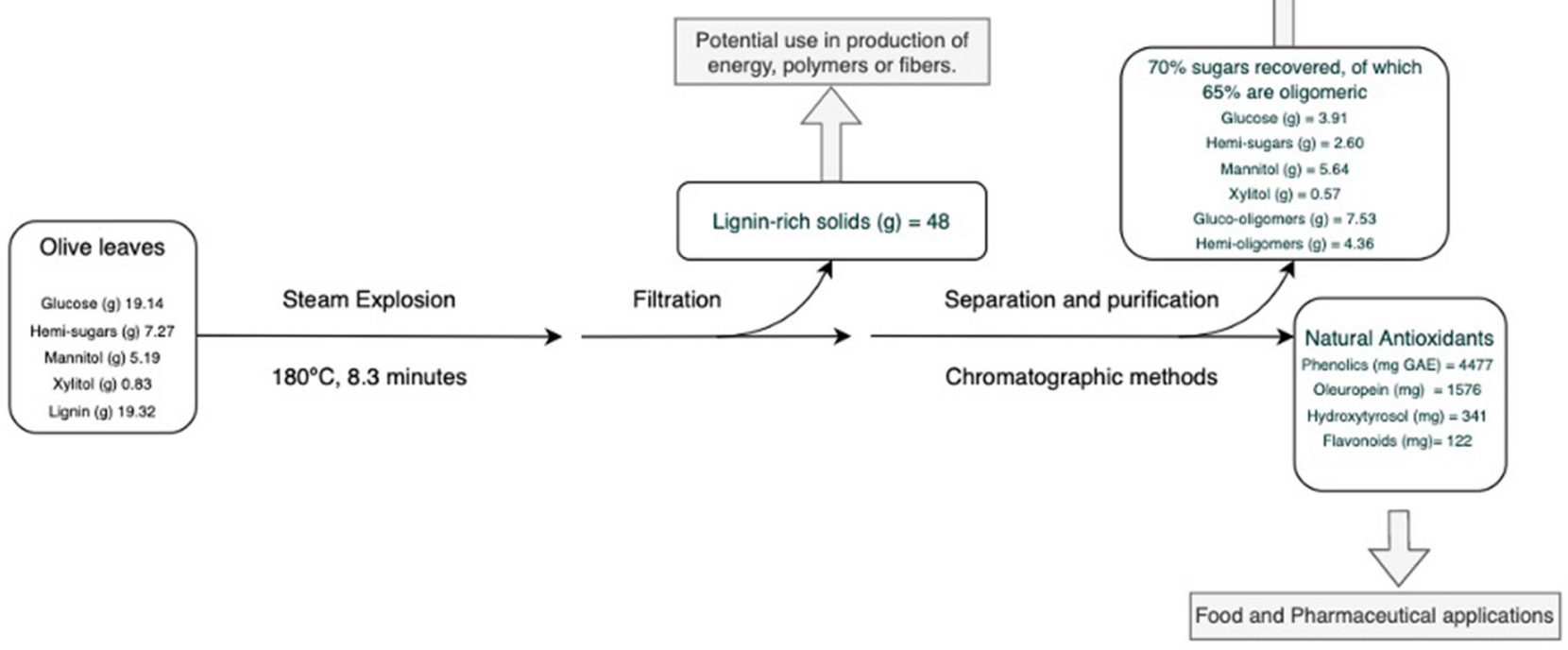

FIGURE 4 | A schematic adapted from Romero-García et al. (2016) which aims to show a process in which all by-products are utilized.

TABLE 6 | The twelve principles of Green Chemistry (Green Chemistry | US EPA, 2021).

\begin{tabular}{|c|c|c|}
\hline Number & Name & Principle \\
\hline 1 & Prevention & Reduce the amount of waste \\
\hline 2 & Atom economy & The final product should aim to contain all the atoms used in the process \\
\hline 3 & $\begin{array}{l}\text { Less hazardous chemical } \\
\text { synthesis }\end{array}$ & $\begin{array}{l}\text { Wherever possible, production methods should be designed to make substances that are less toxic to people or the } \\
\text { environment }\end{array}$ \\
\hline 4 & Designing safer chemicals & Chemical products should be designed to do their job with minimum harm to people or the environment \\
\hline 5 & Safer solvents & Try to avoid the use of solvents and, when these are necessary, choose those that are not harmful to the environment \\
\hline 6 & Design for energy efficiency & $\begin{array}{l}\text { The energy needed to carry out a reaction should be minimized to reduce environmental and economic impact. If possible, } \\
\text { processes should be carried out at ambient temperatures and pressures }\end{array}$ \\
\hline 7 & $\begin{array}{l}\text { Use of renewable } \\
\text { feedstocks }\end{array}$ & A raw material should be renewable whenever possible \\
\hline 8 & Reduce derivatives & Reduce the number of steps in a reaction as this means more reagents are needed and more waste is made \\
\hline 9 & Catalysis & Reactions that are catalyzed are more efficient that uncatalyzed reactions \\
\hline 10 & Design for degradation & $\begin{array}{l}\text { When chemical products are finished with, they should break down into substances that are not toxic and do not stay in the } \\
\text { environment }\end{array}$ \\
\hline 11 & $\begin{array}{l}\text { Real-time analysis for } \\
\text { pollution prevention }\end{array}$ & Methods need to be developed so that harmful products are detected before they are made \\
\hline 12 & $\begin{array}{l}\text { Inherently safer chemistry } \\
\text { for accident prevention }\end{array}$ & $\begin{array}{l}\text { Substances used in a chemical process should be chosen to minimize the risk of chemical accidents, including explosions, } \\
\text { and fire }\end{array}$ \\
\hline
\end{tabular}


vulnerable to physical destabilization, especially at the highest oil concentrations. Hence thee phenolic-rich extracts may be more effective when used in combination with other emulsifiers. Further research has to be carried out to test the efficiency of olive leaf extracts combined with other food emulsifiers as well as with different homogenization conditions (Flamminii et al., 2019).

A recent patent (Musco et al., 2017) provides methods of producing high quality olive leaf powders. The methods comprise blanching fresh olive leaves using infrared radiation, followed by drying and milling the blanched olive leaves to produce a flavorful, colorful and nutritious olive leaf powder. The powders can be used as a basis to manufacture a variety of different food products including but not limited to teas, supplements, nutritional bars and drinks, baby food ingredients, elixirs, pastes, coatings, as well as pharmaceuticals, cosmetics, pesticides, or any olive leaf product in which enhanced antioxidant and antimicrobial properties are desired. This patent has been commercialized successfully in the United States (https://olyxir. com).

\section{DISCUSSION AND PROMISING APPLICATIONS}

With currently more than nine million hectares, olive tree cultivation has spread from the Mediterranean to all over the world, mostly due to the health benefits attributed to olive oil consumption (Sahin and Bilgin, 2017). Despite the economic importance of this food product, olive oil production is associated with negative effects on the environment such as depletion of resources, land degradation, air emissions and the generation of byproducts, the latter of which include large quantities of olive leaves. The leaves are often disregarded despite being promising sources of compounds that could be recovered and used as valuable substances.

In order to optimize the linear model of "take, use and dispose" in the olive oil industry, it must be replaced by a model that respects more the environment, such as a circular model, which aims to maintain the value of the products. And materials for as long as possible, minimizing the generation of recurrence, and if generated, try to give more than one use (Cerdá and Khalilova, 2016).

As explained, the uses for olive leaves can be divided into pharmaceutical, food, new materials, energy and cattle food. The ideal process will minimize the amounts of by-products that end up in landfills, as well as minimizing greenhouse gas emissions.

An efficient way to use the whole olive leaves, would be the one that takes advantage of an entire process that could generate different by-products, each one of those results could be useful in different areas of the industry as has been explained before (Figure 4). A complete process has been already tried at lab scale and was reported as a potential way to obtain sugars and natural antioxidants at the same time (Romero-García et al., 2016).

However, even the processes such as those shown in Figure 4 involve multiple steps and reactions and use solvents for the different chemical and biochemical reactions. In these cases, the necessary approach is to maximize the efficiency of the individual reactions and minimize their hazardous effects to the environment. Whilst no reaction can be entirely "green," the overall negative impact of the chemical and biochemical industry can be reduced by implementing Principles of Green Chemistry (Table 6) (Green Chemistry | US EPA, 2021).

Promising applications focus on the whole leaf matrix. Studies are currently being pursued in the food industry, where the whole leaf is hydrolyzed to obtain higher yields of surfactant compounds, and used as a foam and emulsion stabilizing agent (Flamminii et al., 2019). Other potential research would bemethods mildly hydrolyzing and fermenting the leaf in order to generate possible applications for food and beverages.

\section{AUTHOR CONTRIBUTIONS}

JE, AI, and JL wrote the first draft of the manuscript. All authors contributed to conception and design of the study, manuscript revision, read, and approved the submitted version.

\section{REFERENCES}

Agencia de Información y Control Alimentarios. (2020). Información de Mercados de Aceite. Available online at: https://servicio.mapama. gob.es/informacionmercadoaica/InfMercadosAceite.aao?Aplic=IMA\&O $\% 20$ pcMenu=PROME\&dato_de=PRODUCCION (accessed June 18, 2020).

Alvira, P., Tomás-Pejó, E., Ballesteros, M., and Negro, M. J. (2010). Pretreatment technologies for an efficient bioethanol production process based on enzymatic hydrolysis: a review. Bioresour. Technol. 101, 4851-4861. doi: 10.1016/j.biortech.2009.11.093

Andreadou, I., Sigala, F., Iliodromitis, E. K., Papaefthimiou, M., Sigalas, C., Aligiannis, N., et al. (2007). Acute doxorubicin cardiotoxicity is successfully treated with the phytochemical oleuropein through suppression of oxidative and nitrosative stress. J. Mol. Cell. Cardiol 42, 549-558. doi: 10.1016/j.yjmcc.2006.11.016

Andrikopoulos, N. K, Kaliora, A. C., Assimopoulou, A. N., and Papageorgiou, V. P. (2002). Inhibitory activity of minor polyphenolic and non-polyphenolic constituents of olive oil against in-vitro low-density lipoprotein oxidation. J. Med. Food 5, 1-7. doi: 10.1089/109662002753723160

Apostolakis, A., Grigorakis, S., and Makris, D. P. (2014). Optimisation and comparative kinetics study of polyphenol extraction from olive leaves (Olea europaea) using heated water/glycerol mixtures. Sep. Purif. Technol. 128, 89-95. doi: 10.1016/j.seppur.2014.03.010

Assessment report on Olea europaea L., folium. (2017). Ema.europa.eu. Retrieved from: https://www.ema.europa.eu/en/documents/herbal-report/finalassessment-report-olea-europaea-1-folium-first-version_en.pdf (accessed May 3, 2021).

Athanasiadis, V., Grigorakis, S., Lalas, S., and Makris, D. P. (2017). Highly efficient extraction of antioxidant polyphenols from Olea europaea leaves using an eco-friendly glycerol/glycine deep eutectic solvent. Waste Biomass Valori. 9, 1985-1992. doi: 10.1007/s12649-017-9997-7

Avraamides, M., and Fatta, D. (2008). Resource consumption and emissions from olive oil production: a life cycle inventory case study in cyprus. J. Clean. Prod. 16, 809-821. doi: 10.1016/j.jclepro.2007.04.002

Bahloul, N., Boudhrioua, N., Kouhila, M., and Kechaou, N. (2009). Effect of convective solar drying on colour, total phenols and radical scavenging activity of olive leaves (Olea europaea L.). Int. J. Food Sci. Technol. 44, 2561-2567. doi: 10.1111/j.1365-2621.2009.02084.x 
Balcells, J., Guada, J.A., Castrillo, C., and Gasa, J. (1993). Rumen digestion and urinary excretion of purine derivatives in responses to urea supplementation of sodium-treated straw fed to sheep. Br. J. Nutr. 69, 721-732. doi: 10.1079/BJN19930073

Ben Salah, M., and Abdelmelek, H. (2012). Study of phenolic composition and biological activities assessment of olive leaves from different varieties grown in Tunisia. Med. Chem. 2, 107-111. doi: 10.4172/2161-0444.1000124

Benavente-García, O, Castillo, J, Lorente, J, Ortuño, A, and Del Rio, J. A. (2000). Antioxidant of phenolics extracted from Olea europaea L. leaves. Food Chem. 68, 457-462. doi: 10.1016/S0308-8146(99)00221-6

Boudhrioua, N., Bahloul, N., Ben Slimen, I., and Kechaou, N. (2009). Comparison on the total phenol contents and the color of fresh and infrared dried olive leaves. Industrial Ind. Crops Products. 29, 412-419. doi: 10.1016/j.indcrop.2008.08.001

Bownan, A., and Gansey, G. (2009). The Cambridge Ancient History, Vol 12: The Crisis of Empire, AD 193-337. (Cambridge, MA: Cambridge University Press). p. 717-720.

Campos, P., Miller, A. Z., Knicker, H., Costa-Pereira, M. F., Merino, A., and de la Rosa, J. M. (2020). Chemical, physical and morphological properties of biochars produced from agricultural residues: implications for their use as soil amendment. Waste Manag. 105, 256-267. doi: 10.1016/j.wasman.2020.02.013

Caponio, F, Difonzo, G, Calasso, M, Cosmai, L, and De Angelis, M. (2019). Effects of olive leaf extract addition on fermentative and oxidative processes of table olives and their nutritional properties. Food Res. Int. 116, 1306-1317. doi: 10.1016/j.foodres.2018.10.020

Cara, C., Ruiz, E., Ballesteros, M., Manzanares, P., Negro, M. J., and Castro, E. (2008). Production of fuel ethanol from steam-explosion pretreated olive tree pruning. Fuel 87, 692-700. doi: 10.1016/j.fuel.2007.05.008

Cejudo Bastante, C. (2020). Valorización de los Hojas de Olivo Utilizando Procesos Sostenibles Basados en el uso de la Alta Presión. Oleo. Retrieved from: https:// www.oleorevista.com/?page_id=1002335 (accessed October 03, 2020).

Cejudo Bastante, C., Casas Cardoso, L., Fernández-Ponce, M. T., Mantell Serrano, C., and Martínez de la Ossa, E. J. (2019). Supercritical impregnation of olive leaf extract to obtain bioactive films effective in cherry tomato preservation. Food Packag. Shelf Life 21:100338. doi: 10.1016/j.fpsl.2019.100338

Cerdá, E., and Khalilova, A. (2016). Economía circular. Economía Industrial. 401, 11-20. Retrieved from: https://dialnet.unirioja.es/servlet/articulo?codigo $=$ 5771932 (accessed August 05, 2020).

Cifá, D., Skrt, M., Pittia, P., Di Mattia, C., and Poklar Ulrih, N. (2018). Enhanced yield of oleuropein from olive leaves using ultrasound-assisted extraction. Food Sci. Nutr. 6, 1128-1137. doi: 10.1002/fsn3.654

Costa, P., Dell'Omo, P. P., and La Froscia, S. (2018). Multistage milling and classification for improving both pellet quality and biogas production from hazelnut and olive pruning. Ann. Chim. Sci. Des. Mater. 42, 471-487. doi: 10.3166/acsm.42.471-487

De la Puerta, R, Ruiz Gutierrez, V, and Hoult, J. R. (1999). Inhibition of leukocyte 5-lipoxygenase by phenolics from virgin olive oil. Biochem. Pharmacol. 57, 445-449. doi: 10.1016/S0006-2952(98)00320-7

Díaz, M. J., Huijgen, W. J. J., Van Der Laan, R. R., Reith, J. H., Cara, C., and Castro, E. (2011). Organosolv pretreatment of olive tree biomass for fermentable sugars. Holzforschung 65, 177-183. doi: 10.1515/hf.2011.030

Díaz, M. J., Ruiz, E., Romero, I., Cara, C., Moya, M., and Castro, E. (2009). Inhibition of Pichia stipitis fermentation of hydrolysates from olive tree cuttings. World J. Microbiol. Biotechnol. 25, 891-899. doi: 10.1007/s11274-009-9966-9

Díaz-Villanueva, M. J., Cara-Corpas, C., Ruiz-Ramos, E., Romero-Pulido, I., and Castro-Galiano, E. (2012). Olive tree pruning as an agricultural residue for ethanol production. Fermentation of hydrolysates from dilute acid pretreatment. Span. J. Agric. Res. 10:643. doi: 10.5424/sjar/2012103-2631

Difonzo, G., Squeo, G., Calasso, M., Pasqualone, A., Summo, C., Paradiso, V., et al. (2019). Olive leaf extract as natural preservative. Ital. J. Food Sci. 31, 187-191. Available online at: https://itffs.com/index.php/ijfs/issue/view/36

Flamminii, F., Di Mattia, C., Difonzo, G., Neri, L., Faieta, M., Caponio, F., et al. (2019). From by-product to food ingredient: evaluation of compositional and technological properties of olive-leaf phenolic extracts. J. Sci. Food Agric. 99, 6620-6627. doi: 10.1002/jsfa.9949

Foxhall, L. (2007). Olive Cultivation in Ancient Greece. Great Britain: Oxford University Press.
García Martín, J., Cuevas, M., Feng, C., Álvarez Mateos, P., Torres García, M., and Sánchez, S. (2020). Energetic valorisation of olive biomass: olive-tree pruning, olive stones and pomaces. Processes 8:511. doi: 10.3390/pr8050511

Garcia-Maraver, A., Perez-Jimenez, J., Serrano-Bernardo, F., and Zamorano, M. (2015). Determination and comparison of combustion kinetics parameters of agricultural biomass from olive trees. Renew. Energy 83, 897-904. doi: 10.1016/j.renene.2015.05.049

Ghelichkhani, G., Modaresi, M. H., Rashidi, L., Shariatifar, N., Homapour, M., and Arabameri, M. (2019). Effect of the spray and freeze dryers on the bioactive compounds of olive leaf aqueous extract by chemometrics of HCA and PCA. J. Food Meas. Charact. 13, 2751-2763. doi: 10.1007/s11694-019-00196-3

Ghomari, O., Sounni, F., Massaoudi, Y., Ghanam, J., Drissi Kaitouni, L., Merzouki, M., et al. (2019). Phenolic profile (HPLC-UV) of olive leaves according to extraction procedure and assessment of antibacterial activity. Biotechnol. Rep. 23:e00347. doi: 10.1016/j.btre.2019.e00347

Gong, D, Geng, C, Jiang, L, Wang, L, Yoshimura, H, and Zhong, L. (2012). Mechanisms of olive leaf extract ameliorated rat arthritis caused by kaolin and carrageenan. Phytother. Res. 26, 397-402. doi: 10.1002/ptr.3567

Gonzalez, M., Zarzuelo, A., Gamez, M., Utrilla, M., Jimenez, J., and Osuna, I. (1992). Hypoglycemic activity of olive leaf. Planta Med. 58, 513-515. doi: $10.1055 / \mathrm{s}-2006-961538$

Green Chemistry | US EPA. (2021). US EPA. Retrieved from: https://www.epa.gov/ greenchemistry (accessed May 3, 2021).

Gultekin, F., Yasar, S., Gurbuz, N., and Mermi Ceyhan, B. (2015). Food additives of public concern for their carcinogenicity. J. Nutr. Health Food Sci. 4, 1-6. doi: 10.15226/jnhfs.2015.00149

Herrero, M., Temirzoda, T. N., Segura-Carretero, A., Quirantes, R., Plaza, M., and Ibañez, E. (2011). New possibilities for the valorization of olive oil by-products. J. Chromatogr. A 1218, 7511-7520. doi: 10.1016/j.chroma.2011.04.053

Howell, J. C., and Gawthorne, J. M. (1987). Copper in Animals and Men, Vol. II. Boca Raton, FL: CRC Press; International Olive Oil Council.

Ilias, F., Kholkhal, W., Gaouar, N., Bekhechi, C., and Bekkara Fawzia, A. (2011). Antibacterial and antifungal Activities of olive (Olea europaea L.) from Algeria. J. Microbiol. Biotech Res 1, 69-73. Available online at: https://www. semanticscholar.org/paper/Antibacterial-and-antifungal-Activities-of-oliveFaiza-Wahiba/5770f541e8047c8a7c04735d258cfd4fbc0891f5?sort=relevance\& pdf=true

Impellizzeri, D, Esposito, E, Mazzon, E, Paterniti, I., Di Paola, R., Morittu, V. M., et al. (2011). Oleuropein aglycone, an olive oil compound, ameliorates development of arthritis caused by injection of collagen type II in mice. J. Pharmacol. Exp. Ther. 339, 859-69. doi: 10.1124/jpet.111.182808

International Olive Council. (2007). Production Techniques in Olive Growing. Available online at: http://www.internationaloliveoil.org (accessed May, 2007).

Japón-Luján, R., Luque-Rodríguez, J., and Luque de Castro, M. (2006). Dynamic ultrasound-assisted extraction of oleuropein and related biophenols from olive leaves. J. Chromatogr. A 1108, 76-82. doi: 10.1016/j.chroma.2005.12.106

Karageorgou, I., Grigorakis, S., Lalas, S., and Makris, D. P. (2017). Enhanced extraction of antioxidant polyphenols from Moringa oleifera Lam. leaves using a biomolecule-based low-transition temperature mixture. Eur. Food Res. Technol. 243, 1839-1848. doi: 10.1007/s00217-017-2 887-1

Keskin, D., Ceyhan, N., Ugur, A., and Dbeys, A. D. (2012). Antimicrobial activity and chemical constitutions of West Anatolian olive (Olea europaea L.) leaves. J. Food Agric. Environ. 10, 99-102. Available online at: https://www.wflpublisher. com/Abstract/2896

Korukluoglu, M., Sahan, Y., Yigit, A., Ozer, E. T., and GÜCer, S. (2010). Antibacterial activity and chemical constitutions of Olea europaea 1. leaf extracts. J. Food Process. Preserv. 34, 383-396. doi: $10.1111 / j .1745-4549.2008 .00318 . x$

Lasserre, B., Kaiser, R., Chanh, P. H., Ifansyah, N., Gleye, J., Moulis, C. (1983). PH. Effects on rats of aqueous extracts of plants used in folk medicine as antihypertensive agents. Naturwissenschaften 70, 95-96. doi: $10.1007 /$ BF00365512

Liu, L., Sun, J., Li, M., Wang, S., Pei, H., and Zhang, J. (2009). Enhanced enzymatic hydrolysis and structural features of corn stover by $\mathrm{FeCl}_{3}$ pretreatment. Bioresour. Technol. 100, 5853-5858. doi: 10.1016/j.biortech.2009.06.040

Manzanares, P., Ruiz, E., Ballesteros, M., Negro, M. J., Gallego, F. J., López-Linares, J. C., et al. (2017). Residual biomass potential in olive tree cultivation and olive 
oil industry in Spain: Valorization proposal in a biorefinery context. Span. J. Agric. Res. 15, 1-12. doi: 10.5424/sjar/2017153-10868

March, L., and Ríos, A. (1989). El libro del Aceite de Oliva (1. ${ }^{a}$ edición). Madrid: Alianza Editorial.

Meeks, D. (1993). Oléiculture et viticulture dans l'Égypte pharaonique, in $\mathrm{La}$ production du vin et de l'Huile en Méditerranée (Supplément au bulletin de correspondance hellénique 26), eds M.-C. Amouretti and J.-P. Brun (Athens). p. 3-38.

Mijatovic, S., Timotijevic, G., Miljkovic, D., Radovic, J., Maksimovic-Ivanic, D., Dekanski, D., et al. (2010). Multiple antimelanoma potential of dry olive leaf extract. Int. J. Cancer 128, 1955-1965. doi: 10.1002/ijc.25526

Mkaouar, S., Gelicus, A., Bahloul, N., Allaf, K., and Kechaou, N. (2016). Kinetic study of polyphenols extraction from olive (Olea europaea L.) leaves using instant controlled pressure drop texturing. Sep. Purif. Technol. 161, 165-171. doi: 10.1016/j.seppur.2016.02.002

Molina-Alcaide, E., and Yáñez-Ruiz, D. R. (2008). Potential use of olive byproducts in ruminant feeding: a review. Anim. Feed Sci. Technol. 147, 247-264. doi: 10.1016/j.anifeedsci.2007.09.021

Musco, J., McHugh, T. H., Pan, Z., Avena-Bustillos, R. (2017). Olive Leaf Powder. U. S. Patent No. 9,724,376.

Negro, M. J., Alvarez, C., Ballesteros, I., Romero, I., Ballesteros, M., Castro, E., et al. (2014). Ethanol production from glucose and xylose obtained from steam exploded waterextracted olive tree pruning using phosphoric acid as catalyst. Bioresour. Technol. 153, 101-107. doi: 10.1016/j.biortech.2013.11.079

Neu, H. (1992). The crisis in antibiotic resistance. Science 257, 1064-1073. doi: $10.1126 /$ science. 257.5073 .1064

Özcan, M. M., and Matthäus, B. (2017). A review: benefit and bioactive properties of olive (Olea europaea L.) leaves. Eur. Food Res. Technol. 243, 89-99. doi: 10.1007/s00217-016-2726-9

Rhizopoulou, S. (2007). Olea europaea L. A botanical contribution to culture. A. Eurasian J. Agric. Environ. Sci. 2, 382-387. Available online at: https://www. semanticscholar.org/paper/Olea-europaea-L.-A-Botanical-Contribution-toRhizopoulou/16840dc8303d108c0bf001cc94ca53f6cc4b4ad3\#citing-papers

Romero-García, J., Niño, L., Martínez-Patiño, C., Álvarez, C., Castro, E., and Negro, M. (2014). Biorefinery based on olive biomass. State of the art and future trends. Bioresour. Technol. 159, 421-432. doi: 10.1016/j.biortech.2014.03.062

Romero-García, J. M., Lama-Muñoz, A., Rodríguez-Gutiérrez, G., Moya, M., Ruiz, E., FernándezBolaños, J., et al. (2016). Obtaining sugars and natural antioxidants from olive leaves by steam-explosion. Food Chem. 210, 457-465. doi: 10.1016/j.foodchem.2016.05.003

Sa Santos, J. I., Fillat, Ú., Martín-Sampedro, R., Eugenio, M. E., Negro, M. J., Ballesteros, I., et al. (2017). Evaluation of lignins from sidestreams generated in an olive tree pruning-based biorefinery: bioethanol production and alkaline pulping. Int. J. Biol. Macromol. 105, 238-251. doi: 10.1016/j.ijbiomac.2017.07.030

Sahin, S., and Bilgin, M. (2017). Olive tree (L.) leaf as a waste by-product of table olive and olive oil industry: a review. J. Sci. Food Agric. 98, 1271-1279. doi: $10.1002 /$ jsfa. 8619

Sahin, S., Elhussein, E., Bilgin, M., Lorenzo, J. M., Barba, F. J., and Roohinejad, S. (2018). Effect of drying method on oleuropein, total phenolic content, flavonoid content, and antioxidant activity of olive (Olea europaea) leaf. J. Food Process. Preserv. 42:e13604. doi: 10.1111/jfpp. 13604

Sahin, S., Samli, R., Tan, A. S. B., Barba, F. J., Chemat, F., Cravotto, G., et al. (2017). Solvent-free microwave-assisted extraction of polyphenols from olive tree leaves: antioxidant and antimicrobial properties. Molecules 22:1056. doi: 10.3390/molecules22071056

Salomone, R., and Ioppolo, G. (2012). Environmental impacts of olive oil production: a life cycle assessment case study in the province of Messina (Sicily). J. Clean. Prod. 28, 88-100. doi: 10.1016/j.jclepro.2011.10.004

Sato, H., Genet, C., Strehle, A., Thomas, C., Lobstein, A., Wagner, A., et al. (2007). Antihyperglycemic activity of a TGR5 agonist isolated from Olea europaea. Biochem. Biophys. Res. Commun. 362, 793-798. doi: 10.1016/j.bbrc.2007.06.130

Shahidi, F., and Ambigaipalan, P. (2015). Phenolics and polyphenolics in foods, beverages and spices: Antioxidant activity and health effects - A review. J. Funct. Foods 18, 820-897. doi: 10.1016/j.jff.2015.06.018

Singh, I., Mok, M., Christensen, A. M., Turner, A. H., and Hawley, J. A. (2008). The effects of polyphenols in olive leaves on platelet function. Nutr. Metab. Cardiovasc. Dis. 18, 127-132. doi: 10.1016/j.numecd.2006.09.001

Souilem, S., El-Abbassi, A., Kiai, H., Hafidi, A., Sayadi, S., and Galanakis, C. M. (2017). "Olive oil production sector: environmental effects and sustainability challenges," in Olive Mill Waste: Recent Advances for Sustainable Management, C. M. Galanakis (Elsevier Inc.), 1-28. doi: 10.1016/B978-0-12-805314-0.00001-7

Sudjana, A. N., D’Orazio, C., Ryan, V., Rasool, N., Ng, J., Islam, N., Riley, TV, and Hammer, K. A., et al. (2009). Antimicrobial activity of commercial Olea europaea (olive) leaf extract. Int. J. Antimicrob. Agents 33, 461-463. doi: 10.1016/j.ijantimicag.2008.10.026

Tan, H. W., Tuck, K. L., Stupans, I., and Hayball, P. J. (2003). Simultaneous determination of oleuropein and hydroxytyrosol in rat plasma using liquid chromatography with fluorescence detection. J. Chromatogr $B$ Analyt. Technol. Biomed. Life Sci. 785, 187-191. doi: 10.1016/S1570-0232(02) 00855-3

Tavakoli, H., Hosseini, O., Jafari, S. M., and Katouzian, I. (2018). Evaluation of physicochemical and antioxidant properties of yogurt enriched by olive leaf phenolics within nanoliposomes. J. Agric. Food Chem. 66, 9231-9240. doi: 10.1021 /acs.jafc. 8 b02759

Thorndike, L. (2015). The History of Medieval Europe. Selinsgrove: Perennial Press.

Visioli, F., Poli, A., and Galli, C. (2002). Antioxidant and other biological activities of phenols from olives and olive oil. Med. Res. Rev. 22, 65-75. doi: $10.1002 /$ med.1028

Waterman, E., and Lockwood, B. (2007). Active components and clinical applications of olive oil. Altern. Med. Rev. 12:331.

Weber, M., Salhab, J., Tsatsimpe, K., and Sanchez-Quintela, S. (2019). Olive oil in the North-West of Tunisia: findings from a value chain and jobs survey. Jobs Work. Paper 42, 8-9. doi: 10.1596/33999

Zaragoza, J. R. (1981). La Medicina de los Pueblos Mesopotámicos, Tomo I. Barcelona: Editorial Salvat.

Conflict of Interest: The authors declare that the research was conducted in the absence of any commercial or financial relationships that could be construed as a potential conflict of interest.

Copyright $\odot 2021$ Espeso, Isaza, Lee, Sörensen, Jurado, Avena-Bustillos, Olaizola and Arboleya. This is an open-access article distributed under the terms of the Creative Commons Attribution License (CC BY). The use, distribution or reproduction in other forums is permitted, provided the original author(s) and the copyright owner(s) are credited and that the original publication in this journal is cited, in accordance with accepted academic practice. No use, distribution or reproduction is permitted which does not comply with these terms. 